\title{
Successful Strategies to Engage Students in a COVID-19 Environment
}

\author{
Wiley S. Brown* \\ Department of Business Information Systems and Analytics, North Carolina Agricultural and Technical State University, \\ Greensboro, NC, United States
}

Keywords: COVID-19, communication, student engagement, classroom culture, online education strategies

\section{INTRODUCTION}

On March 11th, 2020, the World Health Organization (WHO) declared COVID-19 as a global pandemic and sent the global economy spiraling into a state of chaos (Adnan, 2020). Higher education like many other industries has had to evolve from the traditional methods which worked in the pre-pandemic world. For most higher education institutions, this meant shifting most if not all classes which were offered face to face to an online environment. This move was not gradual but had to be done essentially overnight to help curve the severity of the virus and keep campuses safe (Dhawan, 2020). Therefore, classes that have never been offered online before were being transitioned to be taught online. This also means that students who may have never taken an online class are now being asked to take an entire load of online classes. Everyone is dealing with different situations, so students, professors, and others involved in higher education have had to try to find the best solutions. This pandemic creates an educational environment that has never been seen before. Therefore, we must embrace previous research and new communication technologies pertaining to online instruction to balance the fears and tensions amidst such crises (Dhawan, 2020).

Due to COVID-19, the classroom culture has changed to a culture of high distraction. Students are now learning from home, surrounded by all their entertainment devices. Yet, despite their distracting environment, they are expected to either log in to class and communicate with their teachers and peers through an entertainment device for which classwork can be one small part of the screen or set their own schedule to regularly engage with an asynchronous learning environment. With all these distractions, educators must engage in strategies to keep their students engaged in order to be effective in the COVID-19 teaching landscape. This paper aims to review research on the strategies that have been found to foster student engagement with online classes. Research was reviewed from both information systems/technology as well as communication to make collective conclusions for helping faculty transition into this new culture.

\section{STUDENT ENGAGEMENT}

Bolliger and Martin (2018) distinguished between three different levels of student engagement.

This article was submitted to Culture and Communication, a section of the journal Frontiers in Communication

Received: 15 December 2020 Accepted: 08 March 2021 Published: 25 March 2021

Citation:

Brown WS (2021) Successful Strategies to Engage Students in a

1. Learner-learner engagement: This includes activities such as discussion boards and other various ways of sharing experiences and resources between students. Notably, a feeling of community and belonging in a class can help students to disclose their experiences allowing students to learn experientially.

2. Learner-instructor engagement: This focuses on communication between the instructor and student, which is an important predictor of student success and achievement. Through modeling positive behaviors and establishing presence, the instructor can foster the learners' sense of community.

3. Learner-content engagement: This consists of the organization of instructional materials and planned activities, which is another component of engagement crucial to student success. In 
other words, it refers to the time students are involved in reviewing instructional content such as textbook, video, audio, and interactive games.

Findings suggest that students and faculty both agreed on the importance of each of these three methods of engagement and that some combination of the three should be used for online learning (Bolliger and Martin, 2018). While all three levels of student engagement are found to be important, it is sometime necessary to prioritize and focus on one or two of these types of engagement depending on the class goals and subject. Students feel that the most valuable elements for engagement in an online class were ensuring instructor presence or personal contact, including relevant course content, and providing frequent communication with the student.

\section{STRATEGIES FOR FOSTERING ENGAGEMENT IN ONLINE COURSES}

Learner-learner engagement can include items such as class introductions or icebreaker activities and collaborative activities. If students are not motivated to engage with one another at the beginning of the semester, the classroom culture will be one of independent study rather than interactivity, so the first 3 weeks are most critical (Kelly and Claus, 2015). Professors must strive to develop a positive rapport between students and engagement in this orientation activity. This means that whatever interactive assignments the students are expected to engage in, so too should the professor to set the example and develop relationships. Being active and encouraging to students as a professor will set an example for how the students should interact with one another. Assignments that foster interactivity should be extended throughout the semester so that students learn from their peers and gain different perspectives on subjects of interest. Grading rubrics should allow students flexibility to expand ideas and should also help to ensure that students are actively interacting with one another in the discussion boards. An alternative to the traditional discussion board model, is hosting discussion boards through Twitter, where students are more likely to engage due to their familiarity with and time naturally spent on the platform (Denker et al., 2018).

Learner-instructor engagement includes regular announcements (email reminders), informal question and answer forums, personalized emails, and discussion board postings, posting grading rubrics for assignments, and creating course orientations (Bolliger and Martin, 2018). Communication between instructor and learner is essential to the success of an online class. Personalized communication (where plausible) is preferred and should continue throughout the entire semester to enhance social presence. Above all, it is critical that students receive messages from the instructor that addresses them by name; this both directly increases students' motivation to engage with subject material and indirectly decreases their classroom anxieties through perceived immediacy (Kelly and Fall, 2011; Kelly and Westerman, 2016). Instructors should consider all communication with students through the lens of that message's potential impact on perceived immediacy and rapport (Culpeper and Kan, 2020). For example, when giving assignment feedback, start with what students did well before explaining everything that was incorrect.

Lastly, learner-content engagement includes items such as working on realistic scenarios, providing structured discussions, and interacting with content in more than one media format. One of the most critical pieces of developing a successful online class is developing a course with high social presence (Kelly and Westerman, 2016). Social presence is the sense of non-mediation, so the more social presence in an online course, the more it feels like a face-to-face course. Developing assignments that have realistic scenarios is essential to engage students in course concepts because it brings a stronger sense of reality to the class so that these concepts feel part of their world, rather than concepts constrained to their learning environment. For example, using real data from local businesses will help show your students that these are not just numbers on a spreadsheet, but that they are data which can be transformed into information that will help this business be successful. It is also important to use richer channels of communication when appropriate to develop social presence between the learner and class content (Kelly and Westerman, 2016). For example, allowing students to read about a concept in their textbook then watch a video about the same concept from an expert in the field will help validate its importance while engaging students with the material across multiple sensory platforms.

\section{DISCUSSION}

Teaching an online class is very different from teaching in a face-to-face environment and when professors try to replicate what they do using technology, it often falls short. The lack of face-to-face interaction with the instructor and increased response time for answering questions can be challenges for online learners (Adnan, 2020). So, educators must move forward in the online environment not attempting to replicate the delivery of their face-to-face courses, but rather adapting them to the online environment, leveraging the strengths of the online classroom vs. the traditional brick and mortar classroom (Kelly and Westerman, 2016).

COVID-19 may have changed the world and higher education forever. It is my hope that we get to return to the classroom for face-to-face instruction soon, but in the meantime, providing a balanced student engagement strategy will help students be more engaged and lead to better learning outcomes. Online education is evolving, and we must strive to continue to develop more efficient ways of creating classroom cultures in online classes that we achieve in face-to-face classes. By putting forth the effort to use classroom technology skillfully and communicating effectively through the online learning platforms, we can provide virtual learning experiences for our students that are as effective as their traditional face-to-face classroom experiences (Kelly and Westerman, 2020).

\section{AUTHOR CONTRIBUTIONS}

The author confirms being the sole contributor of this work and has approved it for publication. 


\section{REFERENCES}

Adnan, M. (2020). Online learning amid the COVID-19 pandemic: students perspectives. J. Pedagogical Res. 1, 45-51. doi: 10.33902/JPSP.2020261309

Bolliger, D. U., and Martin, F. (2018). Instructor and student perceptions of online student engagement strategies. Distance Educ. 39, 568-583. doi: 10.1080/01587919.2018.1520041

Culpeper, J., and Kan, Q. (2020). Communicative styles, rapport, and student engagement: an online peer mentoring scheme. Appl. Linguist. 41, 756-786. doi: 10.1093/applin/amz035

Denker, K. J., Manning, J., Heuett, K. B., and Summers, M. E. (2018). Twitter in the classroom: modeling online communication attitudes and student motivations to connect. Comput. Hum. Behav. 79, 1-8. doi: 10.1016/j.chb.2017.09.037

Dhawan, S. (2020). Online learning: a panacea in the time of COVID-19 crisis. J. Educ. Technol. Syst. 49, 5-22. doi: 10.1177/0047239520934018

Kelly, S., and Claus, C. J. (2015). Practicing nonverbal awareness in the asynchronous online classroom. Commun. Teach. 29, 1-5. doi: 10.1080/17404622.2014.985597

Kelly, S., and Fall, L. T. (2011). An investigation of computer-mediated instructional immediacy in online education: a comparison of graduate and undergraduate students' motivation to learn. J. Advertising Educ. 15, 44-51. doi: $10.1177 / 109804821101500107$

Kelly, S., and Westerman, D. (2020). Doing communication science: thoughts on making more valid claims. Ann. Int. Commun. Assoc. 44, 177-184. doi: $10.1080 / 23808985.2020 .1792789$

Kelly, S., and Westerman, D. K. (2016). "New technologies and distributed learning systems," in Handbooks of Communication Science, Vol. 16, Communication and Learning, ed P. L. Witt (Boston, MA; Berlin: DeGruyter Mouton) 455-480.

Conflict of Interest: The author declares that the research was conducted in the absence of any commercial or financial relationships that could be construed as a potential conflict of interest.

Copyright (c) 2021 Brown. This is an open-access article distributed under the terms of the Creative Commons Attribution License (CC BY). The use, distribution or reproduction in other forums is permitted, provided the original author(s) and the copyright owner(s) are credited and that the original publication in this journal is cited, in accordance with accepted academic practice. No use, distribution or reproduction is permitted which does not comply with these terms. 